\title{
Thermal conductivity and compressive strength anisotropy in vermiculite-ceramic composites with layered structure
}

\author{
Jung-Hye EOM, Young-Wook KIM, ${ }^{\dagger}$ Doo-Hoa JEONG* and Seung-Seok LEE* \\ Functional Ceramics Laboratory, Department of Materials Science and Engineering, University of Seoul, Seoul 130-743, Korea \\ ${ }^{*}$ Hybrid Materials Research Department, Research Institute of Industrial Science \& Technology, Pohang 790-600, Korea
}

\begin{abstract}
High strength vermiculite-ceramic composites with a layered structure were fabricated by adding cellulose fibers as a pore former and by simple uniaxial pressing and subsequent sintering. During uniaxial pressing, the cellulose fibers were aligned perpendicular to the pressing direction and formed an aligned pore structure during sintering. The thermal conductivity $(0.81 \mathrm{~W} / \mathrm{m} \cdot \mathrm{K})$ and compressive strength $(39 \mathrm{MPa})$ of the composite fabricated from 35 mass \% vermiculate, 30 mass $\% \mathrm{SiO}_{2}$, 10 mass \% $\mathrm{Al}_{2} \mathrm{O}_{3}$ and 25 mass \% cellulose fibers, measured perpendicular to the pressing direction, were higher than those $(0.52 \mathrm{~W} / \mathrm{m} \cdot \mathrm{K}$ and $28 \mathrm{MPa})$ measured parallel to the pressing direction. The anisotropy in both thermal conductivity and compressive strength was attributed to the microstructural anisotropy.
\end{abstract}

(C2011 The Ceramic Society of Japan. All rights reserved.

Key-words : Refractory, Thermal insulator, Vermiculite, Layered structure

[Received January 24, 2011 ; Accepted February 16, 2011]

\section{Introduction}

Vermiculite is a nonmetallic mineral classified as one type of mica. It has the peculiar property of expanding rapidly when subjected quickly to high heat because of the almost immediate expulsion of water. Insulating boards made from exfoliated vermiculite are used extensively in industrial applications because of their thermal stability and low thermal conductivity. ${ }^{1)-3)}$ Since vermiculite has no plasticity, clay minerals and/or phosphates are often used as binders for vermiculite boards. ${ }^{4)-7)}$ However, such insulating boards have poor compressive strength (1-4 MPa). ${ }^{3)-5)}$ Progress in mechanical strength has been made in industrial sectors over the last few decades. State-of-art vermiculite boards can be divided into two types: light weight type and high strength type. The light weight type is made purposely to obtain the lowest possible thermal conductivity by sacrificing mechanical strength. The typical thermal conductivity and compressive strength of such boards are $0.2-0.5 \mathrm{~W} / \mathrm{m} \cdot \mathrm{K}$ and $1-5 \mathrm{MPa}$, respectively. In contrast, the high strength type is made to have the highest strength with the help of a binder(s) by sacrificing thermal conductivity. The typical thermal conductivity and compressive strength of such boards are $0.5-0.8 \mathrm{~W} / \mathrm{m} \cdot \mathrm{K}$ and $10-20 \mathrm{MPa}$, respectively. Achieving both low thermal conductivity and high mechanical strength is a challenging issue in the thermal insulating industry.

The incorporation of ceramics in vermiculite is a new approach that has received less attention. Examples include zirconiamodified vermiculite for strontium sorption $^{8)}$ and calcium silicate-vermiculite composites for humidity control and formaldehyde adsorption. ${ }^{9)}$ In this paper, vermiculate-ceramic $\left(\mathrm{SiO}_{2}\right.$, $\mathrm{Al}_{2} \mathrm{O}_{3}, \mathrm{ZrO}_{2}$ ) composites with a layered structure were prepared to improve the mechanical strength of the vermiculate-based boards and reduce the thermal conductivity in a particular direction. The $\mathrm{SiO}_{2}$ and $\mathrm{ZrO}_{2}$ have very low thermal conductivities $\left.(\sim 2 \mathrm{~W} / \mathrm{m} \cdot \mathrm{K})^{10}\right)$ and high temperature stability. In contrast, $\mathrm{Al}_{2} \mathrm{O}_{3}$ has a relatively high thermal conductivity $\left.(30 \mathrm{~W} / \mathrm{m} \cdot \mathrm{K}),{ }^{10}\right)$

\footnotetext{
$\dagger$ Corresponding author: Y.-W. Kim; E-mail: ywkim@uos.ac.kr
}

but it is widely used as a thermal insulation or refractory material because of its excellent thermal and chemical stability at high temperatures. Thus, the three ceramics have been selected for fabricating vermiculate-ceramic composites with layered structure in this study.

\section{Experimental procedure}

Commercially available exfoliated vermiculite $\left[(\mathrm{MgFe}, \mathrm{Al})_{3}-\right.$ $(\mathrm{Al}, \mathrm{Si})_{4} \mathrm{O}_{10}(\mathrm{OH})_{2} \cdot 4 \mathrm{H}_{2} \mathrm{O}, \sim 1.2 \mathrm{~mm}$, density $130-160 \mathrm{~kg} / \mathrm{m}^{3}$, Yuhwa M. S. Co., Incheon, Korea], $\mathrm{SiO}_{2}(\sim 7 \mathrm{~nm}$, Aerosil 300, Evonik Degussa Co. Frankfurt, Germany), $\mathrm{Al}_{2} \mathrm{O}_{3} \quad(\sim 0.4 \mu \mathrm{m}$, 99.9\% pure, Sumitomo Chemical Co., Tokyo, Japan), $\mathrm{ZrO}_{2}$ ( $\sim 20 \mu \mathrm{m}$, Kanto Chemical Co., Tokyo, Japan), and cellulose fiber (BE600/3PU, length $40 \mu \mathrm{m}$, thickness $20 \mu \mathrm{m}$, density $220 \mathrm{~kg} / \mathrm{m}^{3}$, Nycon Materials Co., Ltd., Seoul, Korea) were used as raw materials. Three batches of the powder mixtures were prepared, as shown in Table 1. All batches were milled separately in a polypropylene jar for $24 \mathrm{~h}$ using ethanol and $\mathrm{ZrO}_{2}$ grinding balls. The milled slurry was dried and pressed uniaxially under a pressure of $20 \mathrm{MPa}$. The compacts were then sintered at $1100^{\circ} \mathrm{C}$ for $3 \mathrm{~h}$ in air.

Table 1. Batch composition of vermiculite-ceramic composites with layered structure

\begin{tabular}{cccccc}
\hline \multirow{2}{*}{$\begin{array}{c}\text { Sample } \\
\text { designation }\end{array}$} & Vermiculite $^{1}$ & $\mathrm{SiO}_{2}{ }^{2}$ & $\mathrm{Al}_{2} \mathrm{O}_{3}{ }^{3}$ & $\mathrm{ZrO}_{2}{ }^{4}$ & $\begin{array}{c}\text { Cellulose } \\
\text { fiber }\end{array}$ \\
\cline { 2 - 6 } & 35 & 30 & 5 & 5 & 25 \\
$\mathrm{VC} 1$ & 35 & 30 & 10 & 0 & 25 \\
$\mathrm{VC} 2$ & 35 & 15 & 5 & 20 & 25 \\
$\mathrm{VC} 3$ & &
\end{tabular}

$1 \sim 1.2 \mathrm{~mm}$, density $130-160 \mathrm{~kg} / \mathrm{m}^{3}$, Yuhwa M. S. Co., Incheon, Korea.

$2 \sim 7 \mathrm{~nm}$, Aerosil 300, Evonik Degussa Co. Frankfurt, Germany.

$3 \sim 0.4 \mu \mathrm{m}, 99.9 \%$ pure, Sumitomo Chemical Co., Tokyo, Japan.

$4 \sim 20 \mu \mathrm{m}$, Kanto Chemical Co., Tokyo, Japan.

${ }^{5}$ BE600/3PU, length $40 \mu \mathrm{m}$, thickness $20 \mu \mathrm{m}$, density $220 \mathrm{~kg} / \mathrm{m}^{3}$, Nycon Materials Co., Ltd., Seoul, Korea. 


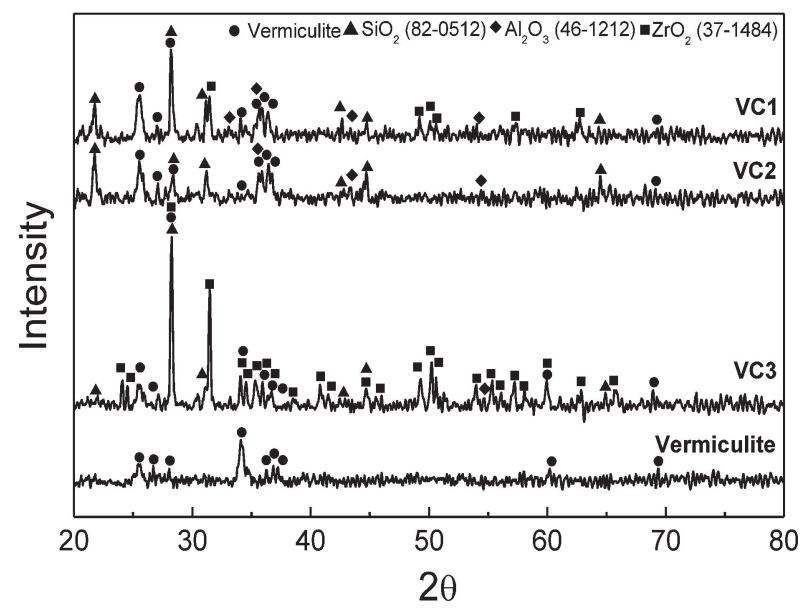

Fig. 1. XRD patterns of vermiculite-ceramic composites sintered at $1100^{\circ} \mathrm{C}$ for $3 \mathrm{~h}$ in air (refer to Table 1$)$.

The bulk density of each sample was calculated from the weight-to-volume ratio. The porosity was determined from the bulk density to true density ratio. The true density was calculated using the rule of mixtures. The fracture surface morphology was observed by scanning electron microscopy (SEM, S4300, Hitachi Ltd., Japan). The compressive strength of samples with a normal size of $5 \mathrm{~mm} \times 5 \mathrm{~mm} \times 10 \mathrm{~mm}$ was measured at a crosshead speed of $0.5 \mathrm{~mm} / \mathrm{min}$ (Instron 4465 , Instron Co., Ltd., USA). The thermal conductivity was measured on plate-shaped specimens $(8 \mathrm{~mm} \times 8 \mathrm{~mm} \times 2 \mathrm{~mm})$ using a laser flash method (LFA 437, MicroFlash $^{\mathrm{TM}}$, Netzsch-Geratebau GmbH, Germany).

\section{Results and discussion}

Figure 1 shows the XRD patterns of all specimens sintered at $1100^{\circ} \mathrm{C}$ for $3 \mathrm{~h}$ in air. XRD pattern of the vermiculite was also included in the figure as a reference. The specimens consisted of their raw materials and no noticeable reaction products between the vermiculite and ceramic materials added were found in the patterns, indicating that the materials are vermiculite-ceramic composites.

The densities of the sintered specimens, VC1, VC2 and VC3, were 1460,1450 and $1500 \mathrm{~kg} / \mathrm{m}^{3}$, respectively. The highest density of $\mathrm{VC} 3$ was attributed to the larger amount of $\mathrm{ZrO}_{2}$ (theoretical density $=5490 \mathrm{~kg} / \mathrm{m}^{3}$ ), leading to the highest theoretical density $\left(3227 \mathrm{~kg} / \mathrm{m}^{3}\right)$, whereas the lowest density of $\mathrm{VC} 2$ was due to the lowest theoretical density $2829 \mathrm{~kg} / \mathrm{m}^{3}$ of the composite. Although the density $\left(1500 \mathrm{~kg} / \mathrm{m}^{3}\right)$ of $\mathrm{VC} 3$ was higher than the others, its porosity $(53.5 \%)$ was higher $(49.1 \%$ for $\mathrm{VC} 1$ and $48.7 \%$ for $\mathrm{VC} 2$ ) because the addition of coarse $(\sim 20 \mu \mathrm{m}) \mathrm{ZrO}_{2}$ suppressed the densification of the composite during sintering.

The microstructures of the sintered specimens were taken from the surfaces parallel (surface $\mathrm{T}$ ) or perpendicular (surface $\mathrm{S}$ ) to the pressing direction. The microstructures of surface $\mathrm{T}$ consisted of vermiculite-ceramic composite and aligned pores (Fig. 2). In contrast, the microstructures of surface $\mathrm{S}$ consisted of plateshaped grains and irregular shaped pores (Fig. 3). The pores were replicated from the cellulose fibers and were preferentially aligned perpendicular to the pressing direction, indicating the alignment of cellulose fibers during pressing. The ceramic powders added were not clearly observed in the microstructure, indicating the formation of vermiculite-ceramic composite grains. The vermiculite-ceramic composite grains were prefer-
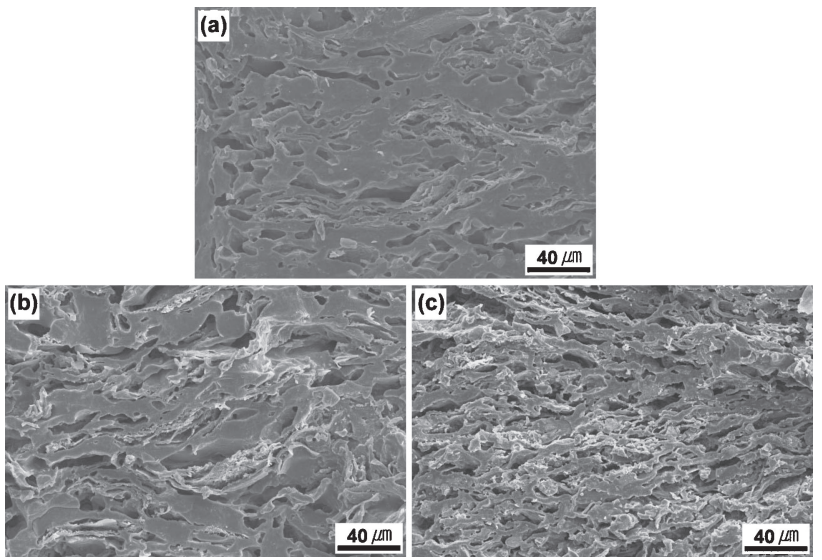

Fig. 2. SEM images of the fracture surfaces of the vermiculite-ceramic composites taken perpendicular to the pressing direction: (a) $\mathrm{VC}$, (b) VC2 and (c) VC3 (refer to Table 1).

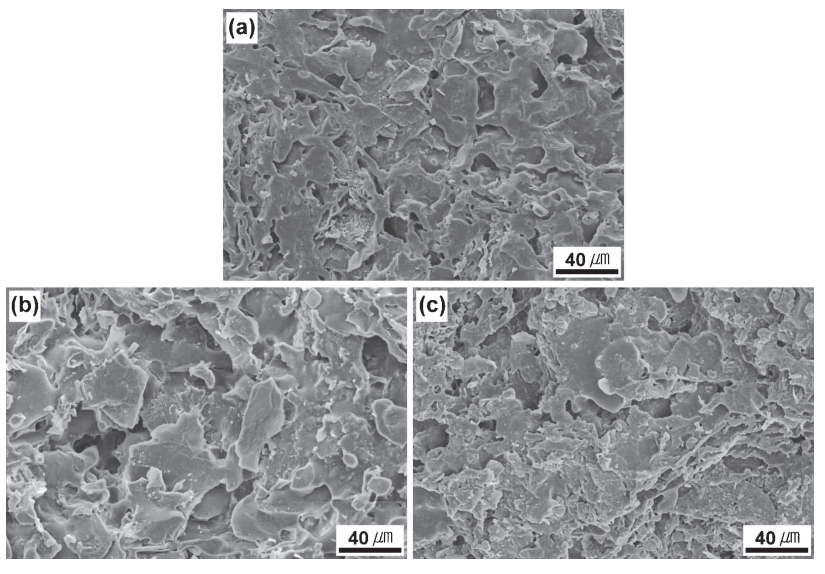

Fig. 3. SEM images of fracture surfaces of the vermiculite-ceramic composites taken parallel to the pressing direction: (a) VC1, (b) VC2 and (c) VC3 (refer to Table 1).

entially aligned perpendicular to the pressing direction due to the alignment of cellulose fibers. Therefore, a layered structure obtained was formed by the addition of cellulose fibers and the use of uniaxial pressing.

Figure 4 shows the thermal conductivity of the specimens. As shown, anisotropy in thermal conductivity was observed in all specimens. The thermal conductivities $(0.43-0.57 \mathrm{~W} / \mathrm{m} \cdot \mathrm{K})$ of the specimens parallel to the pressing direction (S) were lower than those $(0.81-1.13 \mathrm{~W} / \mathrm{m} \cdot \mathrm{K})$ of the specimens vertical to the pressing direction $(\mathrm{T})$. The lower thermal conductivity parallel to the pressing direction was attributed to the larger number of discontinuities in the vermiculite-ceramic composites, i.e. the presence of aligned pores. The aligned pores made heat conduction more difficult than that perpendicular to the pressing direction (T). Therefore, the anisotropy in thermal conductivity was attributed to the anisotropy in the microstructure. The VC3 specimen showed lower thermal conductivity $(0.43 \mathrm{~W} / \mathrm{m} \cdot \mathrm{K}$ for the direction parallel to the pressing direction, and $0.84 \mathrm{~W} / \mathrm{m} \cdot \mathrm{K}$ for the direction perpendicular to the pressing direction) than the other specimens. The addition of a larger amount of $\mathrm{ZrO}_{2}$ (particle size $\sim 20 \mu \mathrm{m}$ ) produced a larger number of layers, i.e., thinner vermiculite-ceramic layers (see Fig. 2) as well as a larger number of discontinuities in thermal conduction, leading to lower thermal conductivity. A large anisotropic thermal conductivity was also reported in synthetic diamond films and rare-earth- 


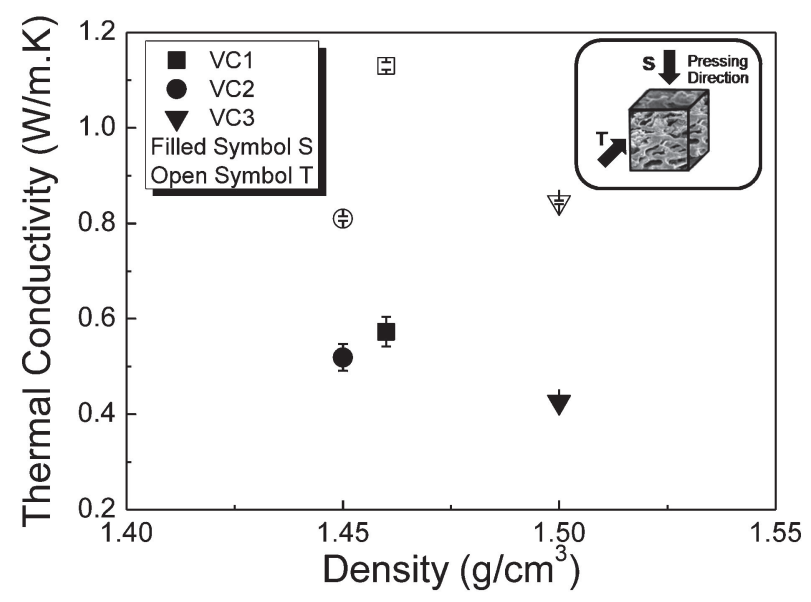

Fig. 4. Thermal conductivity of the vermiculite-ceramic composites as a function of density. $\mathrm{S}$ and $\mathrm{T}$ denote the directions parallel and perpendicular to the pressing direction, respectively.

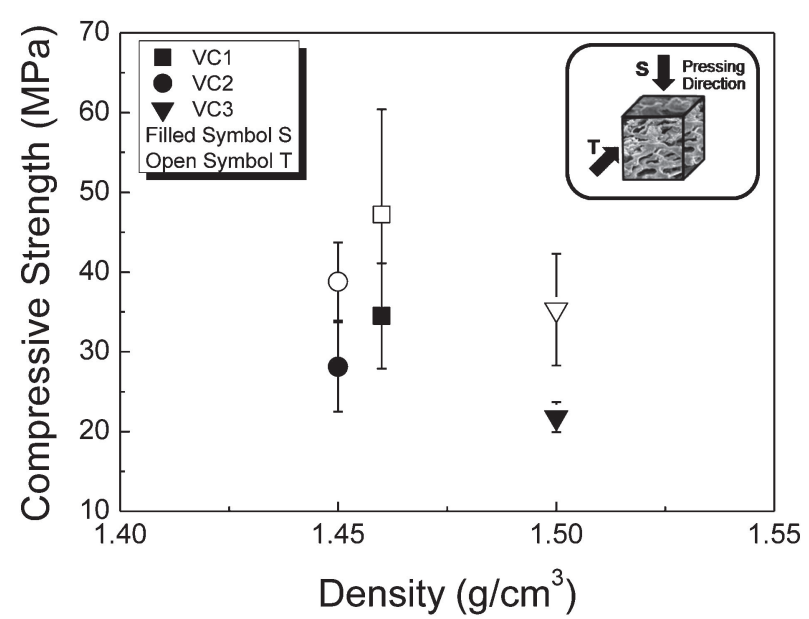

Fig. 5. Compressive strength of the vermiculite-ceramic composites as a function of density. $\mathrm{S}$ and $\mathrm{T}$ denote the directions parallel and perpendicular to the pressing direction, respectively.

transition metal thin films, which was attributed to their microstructure anisotropy. ${ }^{11), 12)}$ However, the influence of the ceramic composition on the thermal conductivity of each specimen cannot be ruled out.

Figure 5 shows the compressive strengths of the specimens. The compressive strengths $(35-47 \mathrm{MPa})$ in the direction perpendicular to the pressing direction $(\mathrm{T})$ were higher than those $(22-35 \mathrm{MPa})$ in the direction parallel to the pressing direction (S). The higher strength in the direction perpendicular to the pressing direction was due to the more robust strut structure and lack of a layered pore structure in the direction than the other, i.e., anisotropy in the microstructure. The $\mathrm{VC} 1$ specimen showed higher strength $(35 \mathrm{MPa}$ in the direction perpendicular to the pressing direction, and $47 \mathrm{MPa}$ in the direction parallel to the pressing direction) than the other specimens. This may be due to the thicker vermiculite-ceramic layer of the specimen than the others, as shown in Fig. 2. The typical compressive strength of commercially available vermiculite insulation boards was in the range of 5-20 MPa. However, the vermiculite-ceramic composites fabricated in the present study showed higher strength $(22-47 \mathrm{MPa})$ than the commercial vermiculite insulation materials. The improved strength of the specimens was attributed to the addition of ceramics $\left(\mathrm{SiO}_{2}, \mathrm{Al}_{2} \mathrm{O}_{3}, \mathrm{ZrO}_{2}\right)$ to vermiculite that acted as an efficient binder for the vermiculite with minimal influence on the thermal conductivity. Combination of the improved strength and the reduced thermal conductivity in a particular direction might make the vermiculite-ceramic composites useful as a thermal insulator for torpedo cars and ladles in steel making industries.

\section{Conclusions}

The addition of cellulose fibers as pore formers led to a layered structure in vermiculite-ceramic composites. The layered structure produced anisotropy in both thermal conductivity and compressive strength. The composite fabricated from 35 mass $\%$ vermiculate, 30 mass $\% \mathrm{SiO}_{2}, 5$ mass $\% \mathrm{Al}_{2} \mathrm{O}_{3}, 5$ mass $\% \mathrm{ZrO}_{2}$ and 25 mass \% cellulose fibers showed the highest compressive strength: 47 and $35 \mathrm{MPa}$ when measured perpendicular and parallel to the pressing direction, respecively. The composite fabricated from 35 mass $\%$ vermiculate, 15 mass $\% \quad \mathrm{SiO}_{2}$, 5 mass $\% \mathrm{Al}_{2} \mathrm{O}_{3}, 20$ mass $\% \mathrm{ZrO}_{2}$ and 25 mass $\%$ cellulose fibers showed lower thermal conductivity than the other composites: 0.43 and $0.84 \mathrm{~W} / \mathrm{m} \cdot \mathrm{K}$ when measured parallel (S) and perpendicular $(\mathrm{T})$ to the pressing direction, respectively.

Acknowledgement This study was supported by a grant from the Research Institute of Industrial Science and Technology (RIST).

\section{References}

1) J. A. Schaeffer, Ind. Eng. Chem., 27, 1298-1303 (1935).

2) L. A. Spitze and L. A. Hansen, Ind. Eng. Chem., 34, 506-508 (1942).

3) M. Tanaka, M. Hattori, T. Tsubaki, M. Oki and O. Kamiike, J. Ceram. Assoc. Jpn., 64, 135-139 (1956).

4) T. Tsubaki, M. Tanaka and O. Kamiike, J. Ceram. Assoc. Jpn., 73, 111-117 (1965).

5) T. Tsubaki and M. Tanaka, J. Ceram. Assoc. Jpn., 80, 105-113 (1972).

6) T. Tsubaki and Y. Kimura, J. Soc. Mater. Sci. Jpn., 34, 228234 (1985).

7) T. Tsubaki and Y. Goto, J. Soc. Mater. Sci. Jpn., 38, 444-450 (1989).

8) M. V. Sivaiah, S. S. Kumar, K. A. Venkatesan, P. Sasidhar, R. M. Krishna and G. S. Murthy, J. Nucl. Radiochem. Sci., 5, 33-36 (2004)

9) M. Akao, Y. Fukuda, A. Yamazaki, M. Inoue, K. Setsu, T. Takagi, K. Rui, M. Okauchi and R. Tamamura, J. Hard Tissue Biol., 15, 101-104 (2006).

10) J. F. Shackelford and W. Alexander, "Materials Science and Engineering Handbook", 3rd ed., CRC Press LLC, Boca Raton, FL, USA (2001).

11) J. E. Graebner, S. Jin, G. W. Kammlott, J. A. Herb and C. F. Gardinier, Nature, 359, 401-403 (1992).

12) L. J. Shaw-Klein, T. K. Hatwar, S. J. Burns, S. D. Jacobs and J. C. Lambropoulos, J. Mater. Res., 7, 329-334 (1992). 